\title{
Time to reinvent the branch of medical pharmacology
}

Sir,

Pharmacology is one of the most active branches of medicine with respect to the amount of research and innovation. The field of pharmacology is actively involved in new drug discovery and identification of new therapeutic targets. However, unfortunately, same cannot be said for the medical pharmacology departments in various medical colleges in India and abroad.

Today, the main function of medical pharmacology department in a medical college is to teach therapeutics and basic pharmacology to medical students. Departmental activities include theory, practical, and tutorial classes for students.

The problem lies with the postgraduate MD programs and departmental clinical activities, which are next to nil in majority of colleges. It is important to analyze the problems individually and then decide whether there is any requirement of reinventing the whole branch and may be introducing some new dimension in work culture as well as curriculum.

The jobs of a medical pharmacologist are mainly in pharmaceutical industries and academics. In pharmaceutical industry, the doctors start as medical advisors (medical writer, investigator, clinical pharmacologist and drug safety physician) with a very lucrative package and this is also the main reason for the attraction of medical graduates for opting this branch. The postgraduates can also join academician in various medical colleges, which is essentially a teaching and research job.

For lasting survival of the branch, the employment opportunities of its students must be ensured by means of a balance in the supply and demand. It has to be ensured that, demand (the vacancies) should be equal or more than the supply (number of postgraduates pass outs).

According to MCI total of 659 (Recognized - $465+$ Permitted - 194) MDs pharmacology pass out every year in India, ${ }^{1}$ so in 5 years, the total number of MDs would be approximately 3300. Taking in account the vacant seats and seats lost due to drop out to be approximately $20 \%$, the 5 years PGs output will be around 2400 . There are more than 170 registered major pharmaceutical companies in India which employs from 0 to 30 or more
MDs at any point of time. ${ }^{2}$ It is almost impossible to find out exact number of vacancies in the industry. However, very generously, taking an average 15 MDs vacancies per company and assuming half of them as vacant, the number of jobs for MD pharmacology in the industry will be 1275 . If the growth of the pharmaceutical industry for the year was taken to be $10-12 \%$ and again assuming that it will remain at least same in next 5 years and increases in net GDP profit also represents the growth in number of jobs, the final number would be $1390 .{ }^{3}$ In academics, the number of jobs is a function of the number of students in that particular medical college. There are 381 medical colleges (Government - 176 + Private - 205) which took admission of 50-250 students each, ${ }^{4}$ taking an average of 150 students, the total number of teachers in pharmacology (as per MCI rules based on student teacher ratio) will be 1 professor, 2 reader and 3 lecturers. According, to MCI a medical college can function even if the staff strength $30 \%$ which means just 2 teachers in a department. ${ }^{5}$ Assuming that almost $50 \%$ of the seats are vacant in all the medical colleges, the actual number of vacant posts for a fresh MD graduate may well be less than 1 per medical college. Hence, the total number of seats will be approximately 355 . Again, assuming the growth of medical colleges (including new medical colleges) would be equal to national GDP growth of 4-7\% (which is difficult to achieve in education) the total number of academic jobs after 5 years would be $380 .^{6,7}$ Therefore, the total number jobs for a new MD pass out after 5 years from now would be approximately $(380+1390) 1770$ as against $2440 \mathrm{MDs}$, that is, a surplus of 670.

It is therefore, imperative to not only reinvent but also grab new opportunities which are arising due to new discoveries in the medical field. One solution of the problem is to go clinical. This would require major policy and curriculum changes in pharmacology. We can start with therapeutics and personalized medicine both are in experimental stages of futuristic medicine. Therapeutics is the branch which concerns with the drug therapy and includes clinical trials, treatment of ADRs, poly-pharmacy prescription, toxicology, therapeutic advice, etc. With a rise of treatment resistance and therapeutic resistance cases in a polypharmacy scenario, a need of "therapeutic care units" is being generated. Manned by a clinical pharmacologist, the "therapeutic care units" will play an important part in advance therapeutics in noncritically ill patients. Personalized medicine is the other and more ambitious approach which includes tailor made 
medicine for each patient that will be done with the help of pharmacogenomics, therapeutic drug monitoring and other physical parameters of the patients. No branch can progress on its own; it requires support of various organizations such as government, corporate hospitals, and industry to achieve sustainable growth. Personalized medicine can catapult medical pharmacology to the likes of fore running branches in medicine as it will be beneficial to government (better patient care), hospitals (generation of capita with more patient centered care) and industry (kits sold for genomic testing, gene based clinical trials, less chances of new drug failure, and withdrawal). Creating opportunities in administration is also necessary. The clinical pharmacologist can well be part of an organization concerned with drug safety. FDA, DCGI, and WHO will be immensely benefitted by a pharmacologist who can have a balance viewpoint with respect to the pharmaceutical industry and health care system in addition to playing a pivotal role in developing guidelines for various health care needs. In all reinventing, medical pharmacology will create more jobs and help in better patient care, which would be a win-win situation for all concerned parties.

\section{Shariq Naeem Syed ${ }^{1 *}$, Piyush Misra1, Bhupinder Kalra ${ }^{1}$, Waseem Rizvi ${ }^{2}$}

${ }^{1}$ Department of Pharmacology, Maulana Azad Medical College, New Delhi - 110 002, India, ${ }^{2}$ Department of Pharmacology, JN Medical College, AMU, Aligarh - 202 002, Uttar Pradesh, India

*Correspondence to: Dr. Shariq Naeem Syed, Email: syedshariq1@gmail.com

\section{REFERENCES}

1. Medical Council of India. MD Pharmacology seats (Recognised-465) in India, 2014. Available from: http://www. mciindia.org/InformationDesk/CollegesCoursesSearch. aspx?N=44. [Last accessed on 2014 Jan 29].

2. List of Pharmaceuticals Companies in India, 2014. Available from: http://www.info.shine.com/ListofCompany/ Pharmaceuticals/819.aspx. [Last accessed on 2014 Jan 29].

3. Indian Brand Equity Foundation. Indian Pharmaceutical Industry, Dec 2013. Available from: http://www.ibef.org/ industry/pharmaceutical-india.aspx. [Last accessed on 2014 Jan 29].

4. MedicalCouncil of India. Number of Medical Colleges in India. Available from: http://www.mciindia.org/InformationDesk/ CollegesCoursesSearch.aspx. [Last accessed 2014 Jan 29].

5. Medical Council of India. Minimum Qualification for Teachers in Medical Institutions Regulations, 1998. Available from: http://www.mciindia.org/RulesandRegulations/ TeachersEligibilityQualifications1998.aspx. [Last accessed on 2014 Jan 29].

6. The World Bank. Indian Annual Growth Rate (\%), 2013. Available from: http://www.data.worldbank.org/indicator/ NY.GDP.MKTP.KD.ZG/countries/IN-8s?display=graph. [Last accessed on 2014 Jan 29].

7. The Economics Time. World Bank cuts India's 2013-14 GDP growth projection to $4.7 \%$, Oct. 2013. Available from: http://www.articles.economictimes.indiatimes. com/2013-10-17/news/43114672_1_india-s-gdp-growthforecast-india-development-report. [Last accessed on 2014 Jan 29].

doi: $10.5455 / 2319-2003 . i j b c p 20140436$

Cite this article as: Syed SN, Misra P, Kalra B, Rizvi W.

Time to reinvent the branch of medical pharmacology. Int J Basic Clin Pharmacol 2014;3:413-4. 